\title{
Studies on Application of Ion Beam Breeding to Industrial Microorganisms at TIARA
}

\author{
Katsuya Satoh * and Yutaka Oono \\ Department of Radiation-Applied Biology Research, Takasaki Advanced Radiation Research Institute, \\ Quantum Beam Science Research Directorate, National Institutes for Quantum and Radiological Science \\ and Technology (QST), 1233 Watanuki, Takasaki, Gunma 370-1292, Japan; ohno.yutaka@qst.go.jp \\ * Correspondence: sato.katsuya@qst.go.jp; Tel.: +81-273-46-9548
}

Received: 17 April 2019; Accepted: 1 June 2019; Published: 5 June 2019

\begin{abstract}
Mutation-breeding technologies are useful tools for the development of new biological resources in plants and microorganisms. In Takasaki Ion Accelerators for Advanced Radiation Application (TIARA) at the National Institutes for Quantum and Radiological Science and Technology, Japan, ion beams were explored as novel mutagens. The mutagenic effects of various ion beams on eukaryotic and prokaryotic microorganisms were described and their application in breeding technology for industrial microorganisms were discussed. Generally, the relative biological effectiveness (RBE) depended on the liner energy transfer (LET) and the highest RBE values were obtained with ${ }^{12} \mathrm{C}^{5+}$ ion beams. The highest mutation frequencies were obtained at radiation doses that gave $1 \%-10 \%$ of surviving fraction. By using ${ }^{12} \mathrm{C}^{5+}$ ion beams in this dose range, many microorganisms have been improved successfully at TIARA. Therefore, ion-beam breeding technology for microorganisms will have applications in many industries, including stable food production, sustainable agriculture, environmental conservation, and development of energy resources in the near future. Moreover, genome analyses of the ion-beam-induced mutants are in progress to clear the differences of mutational functions induced by different LET radiations in microorganisms. Further characterizations of mutations induced by different LET radiations will facilitate more effective use of ion beams in microorganisms breeding.
\end{abstract}

Keywords: ion beam; microorganism; mutagenesis; mutation breeding; TIARA

\section{Introduction}

The growth of the global population increases stable food production in sustainable environmental conditions. It is necessary to expand the variety of available biological resources with functions such as environmental tolerance. Mutation breeding is an applicable technology for expanding variations of biological resources. In plant breeding, >3200 mutant varieties have been generated and registered in the Joint FAO/IAEA Mutant Variety Database [1]. The Joint FAO/IAEA was established by the Food and Agriculture Organization of the United Nations (FAO) and the International Atomic Energy Agency (IAEA). Most mutant varieties were generated by using ionizing radiation, chiefly gamma rays. However, recently, ion beams have been used as novel mutagens, and the number of mutants in the database generated by using ion beams is increasing.

Takasaki Ion Accelerators for Advanced Radiation Application (TIARA), which was established at Takasaki Radiation Research Institute (TARRI), National Institutes for Quantum and Radiological Science and Technology (QST), Takasaki, Japan, is an ion irradiation facility designed to use the features of ion beams for advanced science such as material science and biotechnology. Since the 1990s, QST has been conducting basic research on the induction of mutation in plants using ion beams accelerated by an azimuthally varying field (AVF) cyclotron at TIARA. The AVF cyclotron at TIARA 
can provide various ion beams from $5 \mathrm{MeV}^{1} \mathrm{H}^{+}$to $500 \mathrm{MeV}{ }^{197} \mathrm{Au}^{31+}$ ions and is equipped with ten horizontal beamlines and four vertical branch beamlines [2]. For ion-beams breeding, the ion beams are transported to the irradiation device through a vertical beamline (Figure 1). The vertical beamlines are helpful to irradiate unfixed samples such as tissue culture materials. For uniformly irradiation, ion beams accelerated by the AVF cyclotron were scanned on a $60 \times 60 \mathrm{~mm}^{2}$ area in a vacuum chamber and exited through a 30- $\mu \mathrm{m}$ titanium foil into atmospheric conditions. Target samples were put onto a Petri dish and covered with $7.5 \mu \mathrm{m}$ of kapton polyimide film were irradiated with ion beams at room temperature in the atmospheric conditions (Figure 1C). In research into Arabidopsis thaliana, a widely used model plant, UV-resistant mutants [3], UV-sensitive mutants [4], and mutants in flavonoid transport [5] and in auxin regulation [6] have been successfully generated by ion-beam mutagenesis. The generation of these mutant resources has greatly contributed to understanding the mechanisms of UV response, pigment accumulation, and hormone responses in plants. The biological effects of ion beams, which are high linear energy transfer (LET) radiations, are generally greater than those of low-LET radiation such as gamma rays and electrons $[7,8]$. For instance, the mutation frequency induced in $A$. thaliana by carbon ion beam irradiation was higher than that by electrons $[9,10]$. Therefore, this technology has been applied in horticulture to generate new varieties of ornamental plants. New mutant varieties with such characteristics as flower colors and shapes have been generated in carnation [11], chrysanthemum [12], petunia [13], osteospermum [14], and these novel garden varieties are available commercially. Ion-beam breeding has also been used in the field of sustainable agriculture and applied to generate low-temperature-tolerant netted melons [15], blast-resistant mutants of rice [16], rice mutants that grown well even in low fertilizer conditions [17], and low-cadmium rice [18]. Since the early 1990s, when mutation induction by ion beams was performed for the first time at TIARA, numerous mutagenesis experiments using ion beams have been conducted in higher plants. The characteristics of the mutations induced and mutant varieties generated by ion beams are well-documented in higher plants [19].

Microorganisms are closely associated with human life; for example, they are frequently used for the production of foods and medicines. They are used in a wide range of industries as they have various capabilities to produce, decompose, and accumulate complex chemicals. Although the ion-beam mutation technology has mainly been used for plant breeding, it is also useful for breeding of industrial microorganisms. In QST, we have been working with many collaborators to develop ion-beam technology for generating useful microbial resources that can be used in fields such as agriculture, fermentation, and environmental conservation. This review summarizes our work on ion-beam mutation technology for microorganisms conducted at TIARA. 

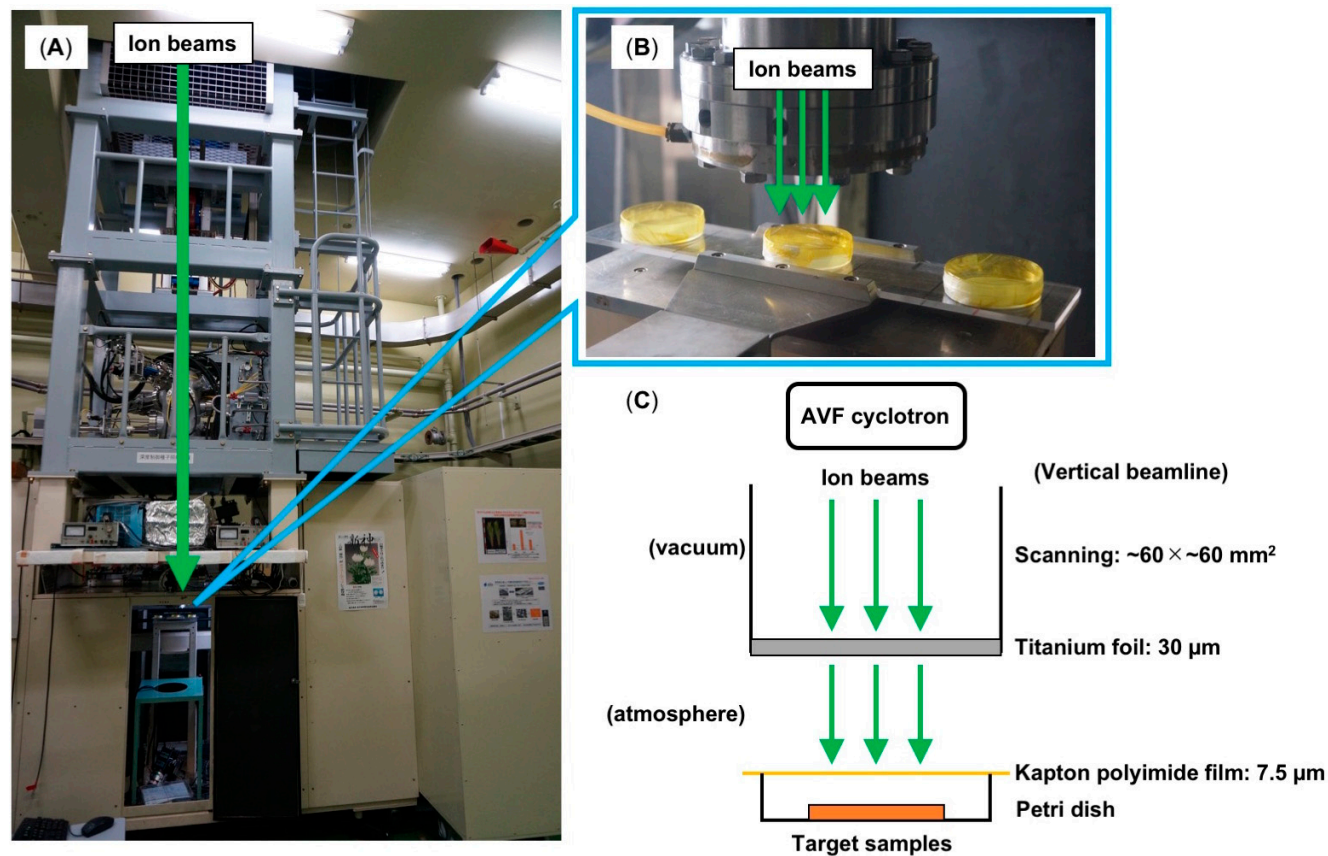

Figure 1. Outline of the ion beams irradiation. (A) Photo of the irradiation device for ion-beam breeding. (B) A magnified view of the irradiation area and target samples. (C) Schematic diagram of ion-beam irradiation. The ion beams were accelerated by the azimuthally varying field (AVF) cyclotron and transported to a vertical beamline. Next, the accelerated ion beams scanned the irradiation area $\left(60 \times 60 \mathrm{~mm}^{2}\right)$ uniformly in a vacuum chamber and exited through a $30-\mu \mathrm{m}$ titanium foil to atmospheric conditions. Finally, the target microorganism samples were irradiated with ion beams at room temperature in the atmospheric conditions.

\section{Mutagenic Effects of Radiations with Different LET in Microorganisms}

Like plants, industrial microorganisms also have been bred to have beneficial properties by conventional mutation methods, mainly using chemicals (ethyl methanesulfonate, methyl methanesulfonate, and $\mathrm{N}$-methyl-N'-nitro-N-nitrosoguanidine), UV, X-rays, and gamma rays as mutagens. However, acquisitions of desired mutants by conventional methods are relatively difficult because of low mutation rates and/or a multitude of mutations. Thus, it takes much time and labor to acquire useful mutants via conventional methods, and it was thus essential to develop a new method for microorganism mutation that could more effectively induce mutations. Ion beams characteristically have high LET and cause high density DNA damage (i.e., clustered damage). In mammalian cells and plants, the relative biological effectiveness (RBE) of ion beams depends on the LET and peaks in the range of LET from about 100 to $400 \mathrm{keV} / \mu \mathrm{m}$ [19-21]. In plants, high-LET ion beams with high RBE can induce different characteristics of mutagenic effects compared with low-LET gamma rays [19]. Therefore, we have been interested in using ion beams for mutation breeding of microorganisms as they could be more effective mutagens than traditional approaches. However, since little was known about the mutagenic effects of ion beams on microorganisms, an investigation on the characteristics of mutations induced by different LET radiations in microorganisms was performed. In most of experiments, five kinds of ion beams $\left({ }^{4} \mathrm{He}^{2+},{ }^{12} \mathrm{C}^{5+},{ }^{12} \mathrm{C}^{6+},{ }^{20} \mathrm{Ne}^{8+}\right.$, and $\left.{ }^{40} \mathrm{Ar}^{13+}\right)$ accelerated by an AVF cyclotron at TIARA were used to irradiate microorganism samples in the atmospheric conditions (Table 1). In all experiments, the prepared microorganism samples that were fixed on a cellulose membrane or agar and put onto a Petri dish were irradiated. At the target surface, the energy of the ion beams passing through the atmosphere and kapton film slightly decreased (Table 1). The penetration range and LET of ion beams were calculated using the IRAC M code [22]. The irradiated dose for microorganism was calculated from the formula: Dose $(\mathrm{Gy})=$ particle fluence $\left(/ \mathrm{cm}^{2}\right) \times \mathrm{LET}(\mathrm{keV} / \mu \mathrm{m})$ $\times$ sample density $\left(\mathrm{g} / \mathrm{cm}^{3}\right) \times 1.6 \times 10^{-9}$. The fluence was calculated from the real-time simultaneous 
measurement value of electric current. For this dose calculation, sample density was expedientially assumed to be $1 \mathrm{~g} / \mathrm{cm}^{3}$. Although the projectile ranges of these ion beams in water are as short as several millimeters, but sufficient to irradiate thin samples such as microorganism cells. Although the projectile ranges of these ion beams in water are as short as several millimeters, but sufficient to irradiate thin samples such as microorganism cells.

Table 1. Properties of ion beams used for mutation breeding at the National Institutes for Quantum and Radiological Science and Technology (QST).

\begin{tabular}{ccccc}
\hline Ion & $\begin{array}{c}\text { Total Accelerated } \\
\text { Energy (MeV) }\end{array}$ & $\begin{array}{c}\text { Total Energy at Target } \\
\text { Surface }(\mathbf{M e V})\end{array}$ & $\begin{array}{c}\text { LET at Target } \\
\text { Surface }(\mathbf{k e V} / \boldsymbol{\mu m})\end{array}$ & $\begin{array}{c}\text { Penetration Range } \\
\text { in Water }(\boldsymbol{\mu m})\end{array}$ \\
\hline${ }^{4} \mathrm{He}^{2+}$ & 50 & 48 & 16 & 1670 \\
${ }^{12} \mathrm{C}^{6+}$ & 320 & 311 & 76 & 2270 \\
${ }^{12} \mathrm{C}^{5+}$ & 220 & 208 & 107 & 1110 \\
${ }^{20} \mathrm{Ne}^{8+}$ & 350 & 316 & 317 & 600 \\
${ }^{40} \mathrm{Ar}^{13+}$ & 460 & 310 & 1550 & 150 \\
\hline
\end{tabular}

Aspergillus oryzae, known as koji mold, is an industrially important microorganism widely used for the production of traditional Japanese fermented foods and beverages such as miso, soy sauce, and sake, as well as for the production of various enzymes used in the industry [23]. To evaluate the effect of ion beams on this filamentous fungus, the lethal effects of different LET radiations on freeze-dried conidia of $A$. oryzae onto the cellulose membranes were investigated, based on the dose required to reduce the surviving fraction to $10 \%\left(D_{10}\right)$. The RBE was calculated by the $D_{10}$ value of ion beams divided by the $\mathrm{D}_{10}$ value of gamma rays. The most effective ionizing radiation in terms of lethal effect among the different LET radiations was the ${ }^{12} \mathrm{C}^{5+}$ ion beam $(107 \mathrm{keV} / \mu \mathrm{m})$, and its RBE value was 4.7. Like other organisms, the RBE for A. oryzae was shown to be dependent on the LET (Figure 2).

Selenate is toxic analog of sulfate, forms selenomethionine by incorporation during the biosynthesis of methionine, and inhibits cell growth. Selenate resistance in A. oryzae is mainly caused by the loss of function of the sulfate permease gene $(s B)$ and/or the ATP sulfurylase gene $(s C)$. Mutagenic effects have been evaluated by monitoring the frequency of selenate resistant mutants (Figure 3). The ${ }^{12} \mathrm{C}^{6+}$ ion beams were the most effective in inducing selenate resistant mutants among three radiations with different LETs. The highest value of mutant frequency $\left(3.47 \times 10^{-3}\right)$ for high-LET ${ }^{12} \mathrm{C}^{6+}$ ion beams was obtained at a dose of $700 \mathrm{~Gy}$, and it was 1.8 times that of low-LET gamma rays $\left(1.93 \times 10^{-3}\right.$ at $1400 \mathrm{~Gy}$; Table 2). The highest value of the mutant frequency with ${ }^{12} \mathrm{C}^{5+}$ ion beams $\left(1.67 \times 10^{-3}\right.$ at $400 \mathrm{~Gy})$ was slightly lower than that with the other two types of radiation. These highest values of mutant frequency were observed in a dose range that gave a surviving fraction of $0.1 \%$ to $1 \%$ for each radiation (Figure 3). The ${ }^{12} \mathrm{C}^{5+}$ ion beams were the most effective in mutation frequency at low doses (200 to 400 Gy). To determine the mutation sites in selenate resistant mutants that were induced by ${ }^{12} \mathrm{C}^{5+}$ ion beams or gamma rays, direct DNA sequencing of genomic PCR products was carried out. The average numbers of mutations per clone in $s B$ and $s C$ for gamma rays (5.26 and 2.06) were four and 1.9 times those generated with ${ }^{12} \mathrm{C}^{5+}$ ion beams (1.30 and 1.09), respectively, indicating that gamma rays tended to generate a multitude of mutations in the same locus of the same clone. In genomic PCR analysis, DNA fragments of either $s B$ or $s C$ loci could not be amplified in $71.25 \%$ and $48.89 \%$ of selenate resistant mutants generated by gamma-rays and ${ }^{12} \mathrm{C}^{5+}$ ion beams, respectively. These failures of the genomic PCR amplification may be attributed to large-scale variations, such as large DNA deletions, translocations, and inversions. Comparative genomic hybridization analysis of a selenate resistant mutant induced by ${ }^{12} \mathrm{C}^{5+}$ ion beams revealed large deletions ( 2 and $340 \mathrm{~kb}$ ). In addition, chromosomal rearrangements by translocation were observed in mutants induced by gamma rays and ion beams (Table 3) [24]. Analyses suggested that high-LET ${ }^{12} \mathrm{C}^{5+}$ ion beams as well as low-LET gamma rays induced base substitutions, frameshifts, deletions, and large-scale mutations in A. oryzae. However, some differences between ${ }^{12} \mathrm{C}^{5+}$ ion beams and gamma rays were observed in the frequencies of these mutations. The results obtained in this pioneering study using $A$. oryzae suggested that ion beams could be used as novel mutagens to develop useful microorganisms, as also demonstrated in plant breeding. 


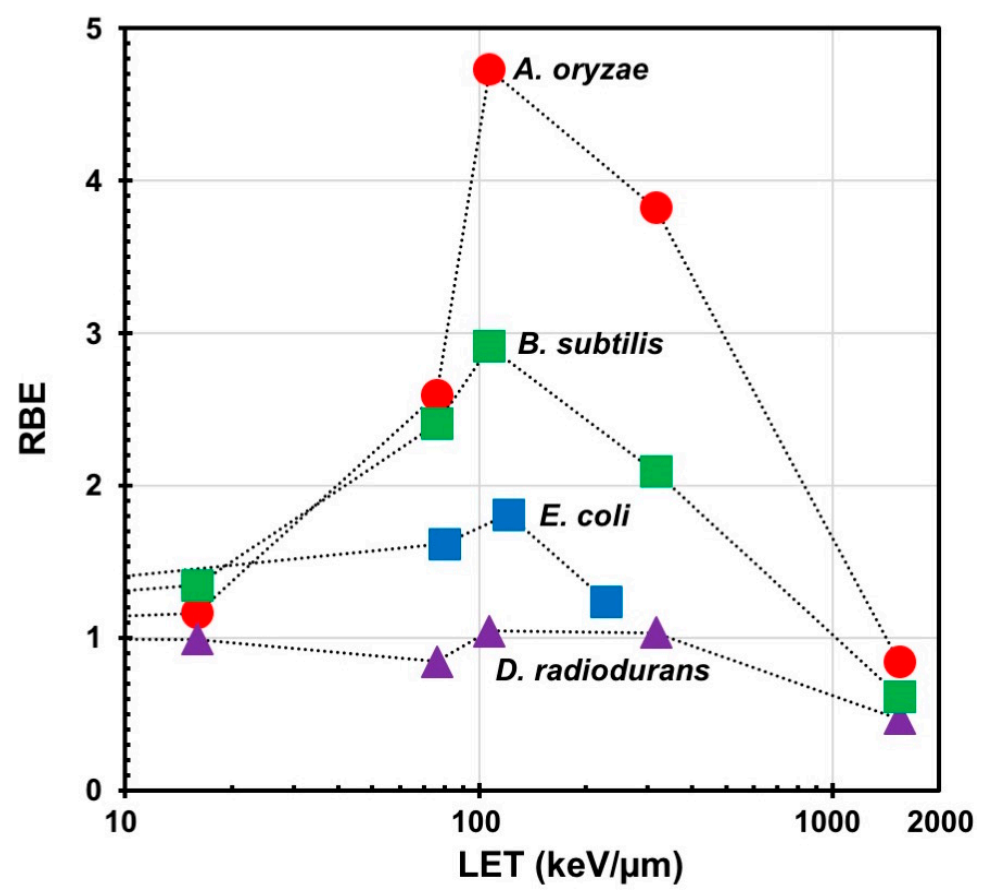

Figure 2. Relative biological effectiveness (RBE) for lethality as a function of linear energy transfer (LET). Data are plotted on the linear (RBE) and logarithmic (LET) scales. Symbols: Red circles, Aspergillus oryzae; blue squares, Escherichia coli; green squares, Bacillus subtilis; purple triangles, Deinococcus radiodurans. Data are modified from [24-27]. RBEs were recalculated based on the LET at the target surface. The highest values of RBE were obtained using $220 \mathrm{MeV}{ }^{12} \mathrm{C}^{5+}$ ion beams for which the LET is $107 \mathrm{keV} / \mu \mathrm{m}$ in all microorganisms tested except $D$. radiodurans, for which no RBE peak was observed because this bacterium was equally resistant to the ion beam and gamma rays.

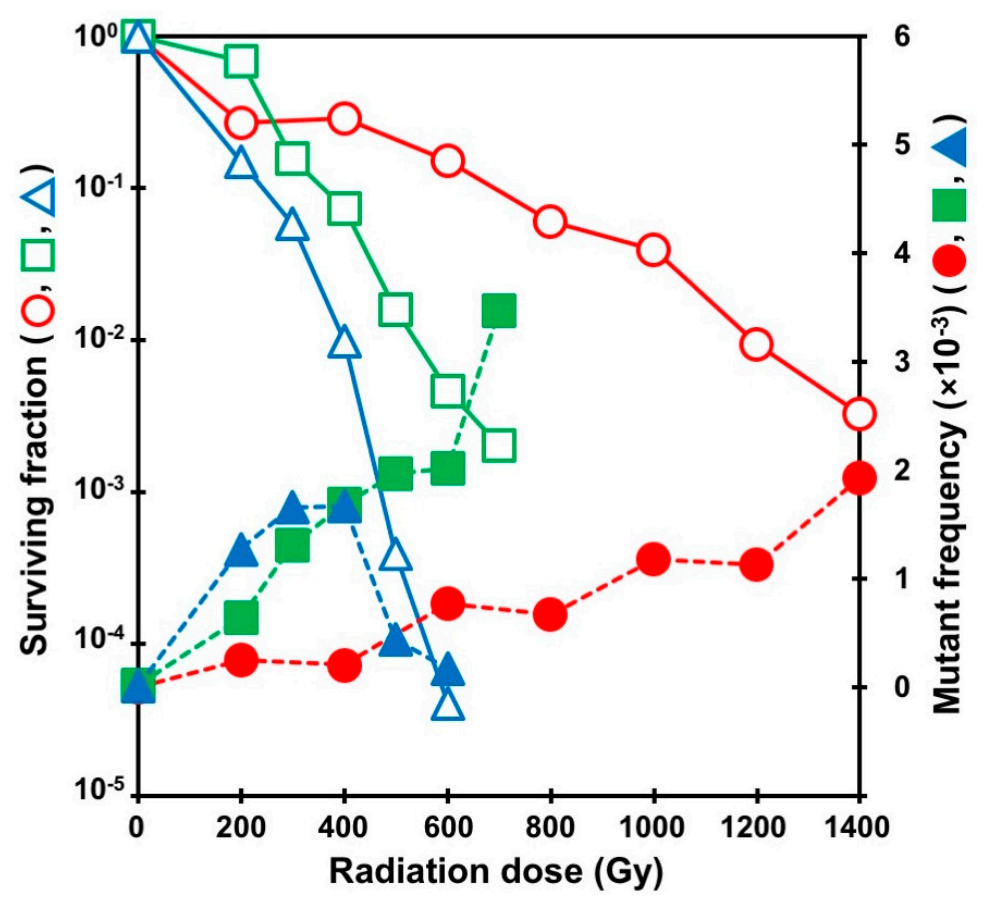

Figure 3. Survival curves and selenate-resistant mutant frequencies in A. oryzae exposed to gamma rays and carbon ion beams. Open and closed symbols indicate surviving fraction and mutant frequency, respectively. Symbols: Circles, gamma rays; squares, ${ }^{12} \mathrm{C}^{6+}$ ion beams; triangles, ${ }^{12} \mathrm{C}^{5+}$ ion beams. Data are modified from Toyoshima et al. (2012) [24]. The highest values of mutant frequency were obtained at a radiation dose giving a surviving fraction of around $0.1 \%$ to $1 \%$. 
Another koji mold, Aspergillus sojae, is also an industrially important microorganism that is used for brewing of soy sauce. Investigation of the effects of ${ }^{4} \mathrm{He}^{2+},{ }^{12} \mathrm{C}^{5+}$, and ${ }^{20} \mathrm{Ne}^{8+}$ ion beams on wet germinated conidia of $A$. sojae onto the agar plates suggested that the ${ }^{12} \mathrm{C}^{5+}$ ion beams had the greatest lethal effect [28]. The lethal effect of ${ }^{4} \mathrm{He}^{2+}$ ion beams was comparable with that of ${ }^{20} \mathrm{Ne}^{8+}$ ion beams. A pyrithiamine is a toxic pyridine analog of thiamine. It inhibits the enzymatic production of thiamine pyrophosphate, an essential cofactor required for biosynthesis of thiamine, and prevents cell growth. Pyrithiamine resistance in $A$. sojae is caused by mutations of the thiA gene. Mutagenic effects were evaluated by monitoring the frequency of pyrithiamine resistant mutants. The highest value of mutant frequency was for ${ }^{12} \mathrm{C}^{5+}$ ion beams $\left(5.60 \times 10^{-5}\right)$, over 20 times higher than that for UV $\left(0.26 \times 10^{-5}\right)$, which is often used as a mutagen in conventional methods (Table 2). The highest value of mutant frequencies obtained using ${ }^{4} \mathrm{He}^{2+}$ and ${ }^{12} \mathrm{C}^{5+}$ ion beams was observed at a dose that resulted in a survival fraction of below $1 \%$, while the dose for ${ }^{20} \mathrm{Ne}^{8+}$ ion beams that resulted in the highest mutant frequency was around $\mathrm{D}_{10}[28]$.

Table 2. Comparison of the highest mutant frequency.

\begin{tabular}{|c|c|c|c|c|}
\hline Microorganism & Radiation & Dose (Gy) & Mutant Frequency & Target Gene \\
\hline \multicolumn{5}{|l|}{ Fungi and Yeast } \\
\hline Aspergillus oryzae & $\begin{array}{c}{ }^{60} \text { Co gamma rays } \\
{ }^{12} C^{5+} \\
{ }^{12} C^{6+}\end{array}$ & $\begin{array}{l}1400 \\
400 \\
700\end{array}$ & $\begin{array}{l}1.93 \times 10^{-3} \\
1.67 \times 10^{-3} \\
3.47 \times 10^{-3}\end{array}$ & $s B$ and $s C$ \\
\hline Aspergillus sojae & $\begin{array}{c}\mathrm{UV} \\
{ }^{4} \mathrm{He}^{2+} \\
{ }^{20} \mathrm{Ne}^{8+} \\
{ }^{12} \mathrm{C}^{5+}\end{array}$ & $\begin{array}{c}\text { No data } \\
300 \\
200 \\
200\end{array}$ & $\begin{array}{l}0.26 \times 10^{-5} \\
3.56 \times 10^{-5} \\
1.88 \times 10^{-5} \\
5.60 \times 10^{-5}\end{array}$ & thiA \\
\hline Saccharomyces cerevisiae & $\begin{array}{l}{ }^{60} \text { Co gamma rays } \\
{ }^{12} C^{5+}\end{array}$ & $\begin{array}{c}66 \\
100\end{array}$ & $\begin{array}{l}0.16 \times 10^{-5} \\
1.85 \times 10^{-5}\end{array}$ & ura3 \\
\hline \multicolumn{5}{|l|}{ Bacteria } \\
\hline Deinococcus radiodurans & $\begin{array}{c}{ }^{60} \text { Co gamma rays } \\
{ }^{4} \mathrm{He}^{2+} \\
{ }^{12} \mathrm{C}^{6+} \\
{ }^{12} \mathrm{C}^{5+} \\
{ }^{20} \mathrm{Ne}^{8+} \\
{ }^{40} \mathrm{Ar}^{13+}\end{array}$ & $\begin{array}{c}8000 \\
6000 \\
6000 \\
6000 \\
8000 \\
15,000\end{array}$ & $\begin{array}{l}1.93 \times 10^{-6} \\
0.92 \times 10^{-6} \\
0.74 \times 10^{-6} \\
1.38 \times 10^{-6} \\
1.71 \times 10^{-6} \\
1.08 \times 10^{-6}\end{array}$ & rров \\
\hline Rhodococcus erythropolis & $\begin{array}{l}{ }^{4} \mathrm{He}^{2+} \\
{ }^{12} \mathrm{C}^{5+}\end{array}$ & $\begin{array}{l}600 \\
800\end{array}$ & $\begin{array}{l}8.67 \times 10^{-7} \\
9.45 \times 10^{-7}\end{array}$ & rpoB \\
\hline
\end{tabular}

Data are modified from $[24,27-30]$.

Table 3. Characteristics of radiation-induced mutations in Aspergillus oryzae.

\begin{tabular}{ccc}
\hline Radiation & ${ }^{\mathbf{6 0}}$ Co Gamma Rays & ${ }^{\mathbf{1 2}^{\mathbf{5}+} \text { Ion Beams }}$ \\
\hline Lethal effect $^{* 1}$ & 1.0 & 4.7 \\
Mutagenic Effect $^{* 2}$ & $1.93 \times 10^{-3}$ & $1.67 \times 10^{-3}$ \\
A multitude of mutations $^{* 3}$ & $5.26,2.06$ & $1.30,1.09$ \\
Large-scale mutations $^{*}$ & $71.25 \%$ & $48.89 \%$ \\
Chromosomal rearrangement $^{*}$ & Observed & Observed \\
\hline
\end{tabular}

${ }^{* 1}$, The RBE is shown; ${ }^{* 2}$, The frequency of the selenate resistant mutant is shown; ${ }^{* 3}$, The average number of mutations per clone in $s B$ and $s C$ genes are shown, respectively; ${ }^{*}$, The frequency of failure of the genomic PCR amplification in $s B$ and/or $s C$ loci is shown; Data are modified from Toyoshima et al. (2012) [24].

Rhizomucor miehei is a fungus used in the industry to produce enzymes required for cheese manufacturing. Investigation of the effects of ${ }^{4} \mathrm{He}^{2+},{ }^{12} \mathrm{C}^{5+},{ }^{20} \mathrm{Ne}^{8+}$, and ${ }^{40} \mathrm{Ar}^{13+}$ ion beams on dried spores of $R h$. miehei onto the Petri dishes showed that the lethal effects of ${ }^{12} \mathrm{C}^{5+}$ and ${ }^{20} \mathrm{Ne}^{8+}$ ion beams 
were about 10 times higher than those of ${ }^{4} \mathrm{He}^{2+}$ and ${ }^{40} \mathrm{Ar}^{13+}$ beams [31]. ${ }^{12} \mathrm{C}^{5+}$ ion beams at a dose that gives a surviving fraction of around $1 \%$ were the best in terms of mutation frequency among the radiations examined [32].

The effects of radiation on the budding yeast Saccharomyces cerevisiae, among the most widely used model eukaryotic microorganisms, have also been investigated by irradiating filtered cells of $S$. cerevisiae with ${ }^{12} \mathrm{C}^{5+}$ ion beams in a dose range from 10 to $300 \mathrm{~Gy}$, and gamma rays. The yeast was much more sensitive to the ${ }^{12} \mathrm{C}^{5+}$ ion beams than to gamma rays. 5-Fluoroorotic acid is a toxic pyrimidine analog of uracil that inhibits pyrimidine biosynthesis by interacting with orotidine-5'-phosphate decarboxylase encoded by the ura3 gene in S. cerevisiae. By disrupting the ura3 gene, 5 -fluoroorotic acid-resistant mutants can be generated. Thus, to evaluate the mutagenic effects of gamma rays and ${ }^{12} \mathrm{C}^{5+}$ ion beams, the 5 -fluoroorotic acid-resistant mutant frequency was determined. The highest value of mutant frequency of ${ }^{12} \mathrm{C}^{5+}$ ion beams was obtained at $100 \mathrm{~Gy}$, and it was over 10 times higher than that of gamma rays at $66 \mathrm{~Gy}$. These highest values of mutant frequency were observed at a dose that resulted in a survival fraction of above $10 \%$ for both types of radiation [29].

The effects of different LET radiations on bacteria have also been investigated. The lethal effects of ${ }^{12} \mathrm{C}^{5+}$ ion beams on wet cells of Escherichia coli, a model gram-negative bacterium, were compared with those of gamma rays. The E. coli cells were much more sensitive to the ${ }^{12} \mathrm{C}^{5+}$ ion beams than to gamma rays (RBE value 1.8; Figure 2) [25]. The lethal effects of ${ }^{12} \mathrm{C}^{5+}$ ion beams on freeze-dried spores of Bacillus subtilis, a model gram-positive bacterium, were also compared with those of gamma rays. The result was the same as for E. coli; the ${ }^{12} \mathrm{C}^{5+}$ ion beams were much more effective (RBE value 2.9; Figure 2) [26]. Freeze-dried cells of Rhodococcus erythropolis, an aerobic gram-positive member of the phylum Actinobacteria, were also more sensitive to ${ }^{12} \mathrm{C}^{5+}$ ion beams than gamma rays $(\mathrm{RBE}=2.1)$. Rifampicin is an antibiotic that inhibits RNA synthesis by directly interacting with the RNA polymerase beta subunit protein encoded by the $r p o B$ gene. By disrupting the $r p o B$ gene in the bacterial genome, rifampicin resistant mutants can be generated. The frequency of rifampicin resistant mutants can be used as an index to evaluate mutagenic effects on bacteria. In R. erythropolis, the frequency of rifampicin resistant mutants increased depending on the radiation dose. The highest mutant frequency for ${ }^{12} \mathrm{C}^{5+}$ ion beams was observed at a dose giving a surviving fraction of around $1 \%$ (Table 2) [30]. The effects of different LET radiations $\left({ }^{4} \mathrm{He}^{2+},{ }^{12} \mathrm{C}^{5+},{ }^{12} \mathrm{C}^{6+}{ }^{20} \mathrm{Ne}^{8+}\right.$, and ${ }^{40} \mathrm{Ar}^{13+}$ ion beams and gamma rays) on another gram-positive bacterium, Deinococcus radiodurans, which is known as a radioresistant bacterium, were also investigated. The degree of radioresistance of freeze-dried $D$. radiodurans cells onto the cellulose membranes irradiated by all ion beams except ${ }^{40} \mathrm{Ar}^{13+}$ was almost equal to that to gamma rays. Ar ion-irradiated cells exhibited a much higher resistance than to the other radiations even at high doses (10 to $15 \mathrm{kGy}$ ). This higher resistance to Ar ion beams was attributed to an overkill effect, in which a much higher ionizing density is deposited on the target than the energy required to inactivate the cell. The rifampicin-resistant-mutant frequencies increased depending on the radiation dose regardless of the type of irradiation [27]. The highest mutant frequencies for all radiations were observed at a dose around $\mathrm{D}_{10}$ (Table 2) [33].

The series of experiments for B. subtilis, R. erythropolis, and D. radiodurans indicated that freeze-dried cells exhibit a higher resistance to gamma-irradiation than wet cells [27,30,34]. These results suggested that the effect of water radiolysis, which caused an indirect action of ionizing radiation, was lower in dry conditions, and that dry conditions could potentially alleviate the generation of mutations in the genome. Since the characteristic biological effects of high-LET radiations are thought to be attributable to direct action rather than indirect action of radiation, use of ion beams in dry conditions may lead to different induced mutations compared with gamma rays. However, since the viability of microorganisms decreases in dry conditions, it is harder to obtain high numbers of colonies after irradiation, and thus it is important to maintain high viability of the microorganisms in dry conditions by adding protective compounds such as skim milk, sodium glutamate, glycerol, or trehalose.

In summary, the RBE in many microorganisms depends on the LET and exhibits a peak in the LET range from about 100 to $400 \mathrm{keV} / \mu \mathrm{m}$ (Figure 2). Exceptionally, no RBE peak is observed for 
D. radiodurans because the resistance of this bacterium to ion beams and gamma radiation is comparable. The dose range that gives a surviving fraction of $1 \%$ to $10 \%$ is effective for inducing mutations with high frequency. By using ${ }^{12} \mathrm{C}^{5+}$ ion beams in this dose range, a wide range of microorganisms have been improved successfully, suggesting that ion beams can be applied to breeding of useful microorganisms for the industry.

\section{Ion-Beam Breeding of Microorganisms}

The ion-beam breeding technology at TIARA has been applied to the development of $>20$ industrial microorganisms, including fungi, microalgae, and bacteria (Table 4). Some examples of applications of ion-beam breeding for improving useful microorganisms are presented below.

Table 4. Breeding of microorganisms using ion-beam breeding technology at the Takasaki Ion Accelerators for Advanced Radiation Application (TIARA).

\begin{tabular}{|c|c|c|c|c|}
\hline Microorganism & Ion & Dose Range (Gy) & Breeding Objective & References \\
\hline \multicolumn{5}{|l|}{ Fungi and Yeast } \\
\hline Aspergillus awamori & ${ }^{12} C^{5+}$ & 100 to 1200 & High amylase activity & [35] \\
\hline Aspergillus sojae & ${ }^{12} C^{5+}$ & 100 to 500 & High producing of protease & [36] \\
\hline Aspergillus usamii & ${ }^{12} C^{5+}$ & 10 to 1000 & $\begin{array}{l}\text { High decompose ability of } \\
\text { dark brown pigments }\end{array}$ & [37] \\
\hline Coriolus versicolor & ${ }^{12} C^{5+}$ & 300 & $\begin{array}{l}\text { High decompose ability of } \\
\text { dark brown pigments }\end{array}$ & [37] \\
\hline Rhizomucor miehei & $\begin{array}{c}{ }^{4} \mathrm{He}^{2+} \\
{ }^{12} \mathrm{C}^{5+} \\
{ }^{20} \mathrm{Ne}^{8+} \\
{ }^{40} \mathrm{Ar}^{13}\end{array}$ & 100,200 & $\begin{array}{l}\text { Low lipase activity } \\
\text { Low coagulation activity }\end{array}$ & {$[31,32]$} \\
\hline Beauveria bassiana & ${ }^{12} C^{5+}$ & 50 to 400 & High fungicide resistance & [38] \\
\hline Isaria fumosorosea & ${ }^{12} C^{5+}$ & 50 to 600 & High fungicide resistance & [39] \\
\hline Metarhizium anisopliae & ${ }^{12} C^{5+}$ & 100 to 500 & High thermotolerance & [40] \\
\hline Pleurotus osutreatus & ${ }^{12} C^{6+}$ & 50 to 1000 & New variety & [41] \\
\hline Lyophyllum decastes & ${ }^{12} C^{6+}$ & 50 to 1000 & New variety & [41] \\
\hline Pleurotus eryngii & ${ }^{12} C^{6+}$ & 50 to 1000 & New variety & [41] \\
\hline Ganoderma lucidum & ${ }^{12} C^{6+}$ & 50 to 1000 & New variety & [41] \\
\hline Grifora flondosa & ${ }^{12} C^{6+}$ & 50 to 1000 & New variety & [41] \\
\hline Alcohol fermentative yeast & ${ }^{12} C^{5+}$ & 10 to 300 & High producing of ethanol & [42] \\
\hline Saccharomyces cerevisiae & ${ }^{12} C^{5+}$ & 50 to 300 & $\begin{array}{l}\text { High producing of ethyl } \\
\text { caproate }\end{array}$ & [43] \\
\hline Zygosaccharomyces rouxii & ${ }^{12} C^{5+}$ & 50 to 300 & Auxotrophy & [44] \\
\hline \multicolumn{5}{|l|}{ Microalgae } \\
\hline Chlamydomonas sp. & ${ }^{12} C^{5+}$ & 50 to 100 & High salinity tolerance & [45] \\
\hline Tisochrysis lutea & ${ }^{12} C^{6+}$ & 5 to 320 & High oil productivity & [46] \\
\hline \multicolumn{5}{|l|}{ Bacteria } \\
\hline Bradyrhizobium japonicum & $\begin{array}{c}{ }^{12} \mathrm{C}^{5} \\
{ }^{4} \mathrm{He}^{2+} \\
{ }^{12} \mathrm{C}^{6+}\end{array}$ & 50 to 800 & High thermotolerance & [47] \\
\hline Deinococcus radiodurans & $\begin{array}{c}{ }^{12} \mathrm{C}^{5+} \\
{ }^{20} \mathrm{Ne}^{8+} \\
{ }^{40} \mathrm{Ar}^{13}\end{array}$ & 2000 to 20000 & Cs-accumulating ability & [48] \\
\hline Pseudomonas fluorescens & ${ }^{12} C^{5+}$ & 10 to 300 & $\begin{array}{l}\text { High suppression effect of } \\
\text { tomato bacterial wilt }\end{array}$ & [49] \\
\hline Rhodococcus erythropolis & ${ }^{12} C^{5+}$ & 200 to 2000 & Cs-accumulating ability & [30] \\
\hline Streptomyces coelicolor & ${ }^{12} C^{5+}$ & 10 to 1000 & Pigment producing ability & [50] \\
\hline
\end{tabular}

\subsection{Sake Brewing}

Sake is a traditional liquor made from rice, but sake consumption has been decreasing year by year in Japan. To elevate sake consumption, it is important to quickly generate new varieties of sake, meeting the needs of the market. In addition to alcohol fermentation, sake yeast has a key role in producing its own flavor and taste characteristics. Ethyl caproate is an important flavor component in 
Ginjo-shu (sake brewed with highly polished rice). Therefore, the breeding of sake yeast (S. cerevisiae) for high production of ethyl caproate has been attempted by using ion-beam breeding technology. Freeze-dried sake yeasts onto the cellulose membranes were irradiated with ${ }^{12} \mathrm{C}^{5+}$ ion beams in the dose range 50 to $300 \mathrm{~Gy}$ (Table 4). The most effective dose was $125 \mathrm{~Gy}$. Following irradiation, over 2000 cerulenin-resistant sake yeast mutants were isolated. Ethyl caproate is biosynthesized from caproic acid, a medium-chain fatty acid, and ethanol. Cerulenin inhibits long-chain fatty acid synthesis. It was therefore expected that the productivity of medium-chain fatty acids including caproic acid (and hence ethyl caproate) would be different in cerulenin-resistant mutants from that in the parental strain. A high-ethyl-caproate-producing strain was selected from among the mutants. The production of ethyl caproate in the novel strain of sake yeast $(7.4 \mathrm{ppm})$ was 4.6 times that in the parental strain (1.6 ppm; Figure 4). The novel yeast was shown to have the potential for commercial brewing by test brewing for three years [43]; Ginjo-shu prepared using this novel stain of sake yeast has been commercially available since April 2013. To find factors contributing to the high productivity of ethyl caproate in the novel yeast, DNA sequences of fatty acid synthase genes (FAS1 and FAS2) and fatty acid esterase genes (EHT1 and EEB1) that are involved in ethyl caproate production have been analyzed. No mutation was found in the EHT1, EEB1, and FAS1 loci compared with the parental strain. However, the novel sake yeast strain carried a mutation ( $\mathrm{G}$ to $\mathrm{A}$ ) at nucleotide position 3748 in the FAS2 gene. This mutation causes an amino acid substitution at position 1250 (Gly to Ser, G1250S) in the FAS2 protein [51]. Recombinant sake yeast carrying the same mutation in FAS2 exhibits a high ethyl caproate production phenotype [52], suggesting that the higher production of ethyl caproate in the sake yeast generated by ion-beam breeding is attributable to this dominant mutation in the FAS2 gene.

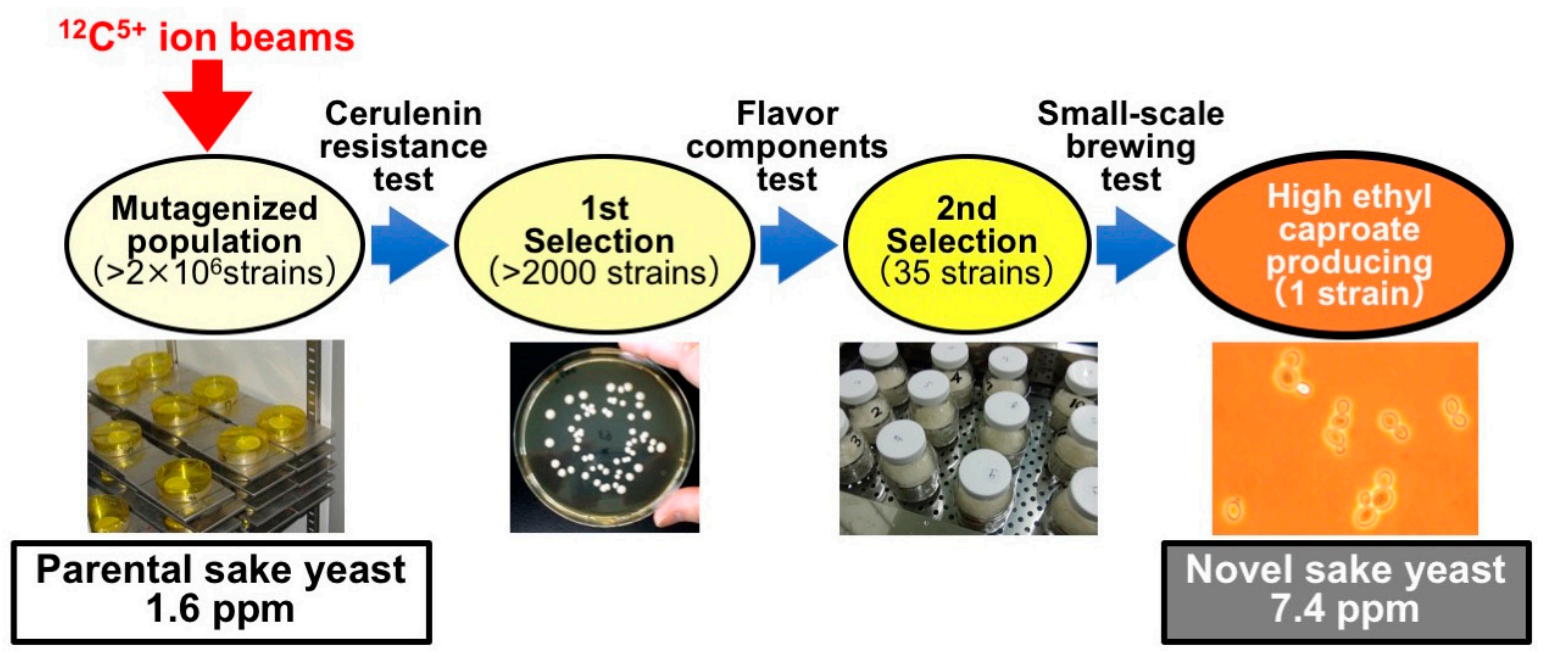

Figure 4. Development of high-ethyl caproate-producing sake yeast (Saccharomyces cerevisiae) by ion-beam irradiation. As the first selection, $>2000$ cerulenin-resistant mutants were isolated from a mutagenized population of sake yeast, which was generated by carbon-ion-beam irradiation. Next, 35 mutants were selected based on the amount of flavor components produced, including ethyl caproate. Finally, a high-ethyl caproate-producing sake yeast was identified by small-scale brewing tests. The novel sake yeast strain obtained exhibited over four times the ethyl caproate producing ability of the parental strain.

\subsection{Industrial Enzyme Productions}

Proteases and peptidases are very important enzymes in soy sauce production. These enzymes hydrolyze soybean and wheat proteins to peptides and amino acids, which form the basis for the taste of soy sauce. Therefore, mutants with high ability to produce proteases and/or peptidases are desired by the soy sauce industry. However, even if high-enzyme-producing mutants are acquired by conventional mutation methods, most such mutants have simultaneous undesirable characteristics, such as slow growth rate and decreased activity of other important enzymes, for example peptidase 
and glutaminase. Therefore, ion beams were considered as alternative mutagens and wet conidia of $A$. sojae onto the agar plates were irradiated with ${ }^{12} \mathrm{C}^{5+}$ ion beams in the dose range of 100 to 500 Gy (Table 4). The most effective dose to induce mutant was $250 \mathrm{~Gy}$. Following irradiation, high-protease-producing mutants were screened by observing the size of the halo around colonies on casein plates, and six high-protease-producing mutants were obtained. The protease activities of the mutants (about 1100-1930 U/g strain) were over two times higher than that of the parental strain (500-650 U/g strain) [36]. In this case, 1 unit (U) of the protease activity is showed as the amount that generates $1 \mu \mathrm{mol}$ of tyrosine in 1 minute per $1 \mathrm{~g}$ of $A$. sojae. While, productions of the peptidase and glutaminase were comparable in the mutant and parental strains. It was found in test brewing that the mutants could make a very strong tasting soy sauce, implying that they have the potential for practical use in soy sauce production [36].

Amylase is a very important enzyme that digests starch. For the effective use of starchy crops such as wheat, corn, potatoes, and cassava, it is important to digest raw starches for the industrial fermentation process. Aspergillus awamori is a fungus used to produce an acidophilic amylase. The high amylase activity mutants could not be acquired by a conventional breeding method by UV. Therefore, for increasing of amylase activity, freeze-dried spores of $A$. awamori onto the membranes were irradiated ${ }^{12} \mathrm{C}^{5+}$ ion beams in the dose range of 100 to $1200 \mathrm{~Gy}$. The most effective dose to induce a mutant was 750 Gy. Following irradiation, the black colored and large size colonies were selected, tested their amylase activity individually, and three high amylase activity mutants were obtained. The amylase activities of the mutants (about 3500-5800 IU/L) were 1.4 to 2.4 times higher than that of the parental strain (2400 IU/L) [35]. In this case, IU means the amount of enzyme releasing reducing sugar equivalent to $1 \mu \mathrm{mol}$ of glucose per one minute. Moreover, the frequency to induce useful mutant strains with high amylase activity was five to 10 times higher in ${ }^{12} \mathrm{C}^{5+}$ ion-beams irradiated samples than in gamma-irradiated ones [35].

\subsection{Biopesticides}

In addition to microorganisms for the use in the fermentation industry, ion-beam breeding technology has been applied to develop microorganisms for the use in agriculture and environmental technologies. The entomopathogenic fungi Isaria fumosorosea, Beauveria bassiana, and Metarhizium anisopliae are important agents for the biological control of insect pests and are commercially available as biopesticides. However, these fungi are highly susceptible to chemical fungicides used to protect plants from diseases such as powdery mildew. Thus, if biopesticides are used together with chemical fungicides, the biological control potential of the biopesticide is reduced. In addition, these fungi are susceptible to high temperatures. To overcome these problems, ion-beam breeding technology was applied to generate fungicide-resistant or thermotolerant mutants. Dried conidia of I. fumosorosea, B. bassiana, and M. anisopliae onto the cellulose membranes were irradiated with ${ }^{12} \mathrm{C}^{5+}$ ion beams in the dose range of 50 to $600 \mathrm{~Gy}$ (Table 4). The most effective doses to induce mutants of I. fumosorosea, B. bassiana, and M. anisopliae were 300, 150, and $300 \mathrm{~Gy}$, respectively. For fungicide resistance, the mutants were screened in an inhibitory concentration of benomyl, a major fungicide. The obtained benomyl-resistant mutants of I. fumosorosea (survived in benomyl concentrations $>5000 \mathrm{mg} / \mathrm{L}$ ) and B. bassiana $(>500 \mathrm{mg} / \mathrm{L}$ ) were over 2000 and 500 times more resistant than the parental strains ( 2.5 and $1 \mathrm{mg} / \mathrm{L}$, respectively) $[38,39]$. To select thermotolerant mutants, the irradiated conidia were cultivated at a high temperature $\left(38 \pm 1{ }^{\circ} \mathrm{C}\right)$, which was high enough to prevent the growth of the parental strains. Thermotolerant mutants of M. anisopliae showed an upper limit for vegetative growth of $38-39{ }^{\circ} \mathrm{C}$, two to three degrees higher than the parental strain $\left(36{ }^{\circ} \mathrm{C}\right)$ [40]. These useful mutants of entomopathogenic fungi were obtained without reducing their biological control potential, and expected to be used as new biopesticides. 


\subsection{Biofertilizers}

Bradyrhizobium japonicum is a rhizobium that has the ability to elicit the formation of special organs called nodules on leguminous host roots for symbiotic nitrogen fixation. It is used in biofertilizer inoculants that promote plant growth. The development of biofertilizers has been progressed in Asian countries to increase crop yield under low input of chemical fertilizers. However, there is a problem with the use of B. japonicum biofertilizers, especially in south Asian countries, because they easily lose viability at a high temperature and under drought stress, including during storage and transportation. The thermotolerant mutant is desirable. For this purpose, freeze-dried B. japonicum cells onto the cellulose membranes were irradiated with ${ }^{12} \mathrm{C}^{5+}$ ion beams in the dose range of 50 to $800 \mathrm{~Gy}$ (Table 4). The thermotolerant mutant was obtained from cells irradiated at $300 \mathrm{~Gy}$. The mutant could survive at $42{ }^{\circ} \mathrm{C}$, at which growth of the parental strain is prevented, without affecting the nodulation and nitrogen fixation abilities [47]. This thermotolerant mutant is expected to be used as a new biofertilizer inoculant. To clarify factors contributing to the high thermotolerance, the whole genome sequence of the mutant has been analyzed. Although detailed analyses of the mutated genes are still in progress, genome comparison analysis revealed that a large-scale structural change (an inversion of $1.27 \mathrm{Mb}$ ) and 18 single base substitutions occurred in the 9.11-Mb chromosome of the mutant [53].

\subsection{Bioremediation}

Microorganisms have often been used to develop bioremediation technologies to remove and recover contaminated environments. Since the Fukushima Daiichi nuclear disaster, removing radioactive caesium from contaminated soil has been one of the most important issues in Japan. In this context we have worked on bacterial strains, R. erythropolis CS98 that was isolated from soil as a radioactive Cs-accumulating bacterium [54], and D. radiodurans, which also possesses a Cs-accumulating ability [55], to investigate mechanisms of Cs accumulation in these bacteria. To generate mutants with altered Cs-accumulating ability, freeze-dried cells of R. erythropolis CS98 and D. radiodurans onto the cellulose membranes were irradiated with ${ }^{12} \mathrm{C}^{5+}$ ion beams in the dose ranges of 200 to 2000 and 2000 to 20000 Gy, respectively (Table 4). The effective dose of $R$. erythropolis CS98 and D. radiodurans were 800 and $8000 \mathrm{~Gy}$, respectively, that resulted in a surviving fraction of $1 \%$ to $10 \%$. Mutants with an altered Cs-accumulating ability were screened by measuring intracellular Cs levels using an atomic absorption spectrometer. Consequently, candidates of low Cs-accumulating mutants of R. erythropolis CS98 [30] and high Cs-accumulating mutants of D. radiodurans were obtained [48]. Genome analyses of the mutants are still in progress and will clarify the factors involved in Cs-accumulation.

\subsection{Biofuels}

Biofuels, including bioethanol and biological oils, which are produced through metabolic processes in yeasts or microalgae, have recently attracted significant attention as candidate renewable energy sources. Highly efficient production of biofuels from non-edible biomass resources, such as starch and lignocellulose, is a very important issue for the biomass industry. During bioethanol production in yeast, ethanol production is negatively affected when cells are exposed to a high temperature and toxic compounds derived from chemical pretreatment processes or hydrolyzation for saccharification and fermentation of the substrate [56]. Therefore, the development of mutants that are tolerant to a high temperature and toxic compounds is desirable. To obtain such mutants, wet cells of alcohol fermentative yeast onto agar plates were irradiated with ${ }^{12} \mathrm{C}^{5+}$ ion beams in the dose range of 10 to $300 \mathrm{~Gy}$ (Table 4). For inducing a mutant, the dose at $200 \mathrm{~Gy}$ was the most effective. A high-ethanol-producing mutant was obtained by screening at a high temperature $\left(35^{\circ} \mathrm{C}\right)$ in medium containing bagasse sugar lysate as a toxic compound [42]. The ethanol producing ability of the mutant (about $20 \mathrm{~g} / \mathrm{L}$ ) was over three times that by the parental strain (about $6 \mathrm{~g} / \mathrm{L}$ ) [57].

Microalgae are promising biofuel producers because their lipid productivity per unit area is higher than that of land plants, and sea water can be used for mass culture [58]. The salinity tolerance and high 
lipid productivity are important factors. To improve the salinity tolerance and lipid productivity of a typical microalga, wet cells of the Chlamydomonas sp. onto the agar plates were irradiated with ${ }^{12} \mathrm{C}^{5+}$ ion beams at 50 or $100 \mathrm{~Gy}$ (Table 4). As a result, high-salinity-tolerant mutants with an ability to grow in $7 \%$ sea salt were obtained [45]. The salinity-tolerant mutants exhibited high biomass production (about $4.1 \mathrm{~g} / \mathrm{L}$ ) in the high salt conditions, in which the parental strain could hardly produce biomass (about $0.3 \mathrm{~g} / \mathrm{L}$ ) [45].

The results described above suggest that ion beams can be used as powerful mutagens and are effective for breeding industrial microorganisms. Therefore, it could greatly contribute to various fields, such as securing stable food production, agriculture, environmental conservation, and the development of bioenergy resources, using ion-beam breeding technology.

\section{Ion-Beam Breeding of Microorganisms in Other Facilities}

In addition to TIARA at QST, irradiation facilities that can be used for ion-beam breeding technology in Japan are the RI Beam Factory at RIKEN (RIBF) [59], the Multi-purpose Accelerator System with Synchrotron and Tandem at the Wakasa Wan Energy Research Center (W-MAST) [60], and the Heavy Ion Medical Accelerator in Chiba (HIMAC) at the National Institute of Radiological Sciences, QST [61]. In China, ion beams are applied for improving microorganisms at the Heavy Ion Research Facility in Lanzhou (HIRFL), the Institute of Modern Physics, Chinese Academy of Sciences [62]. Other Asian countries are also paying attention to the use of ion beams for mutation breeding. Recently, the ion-beam breeding technology at RIBF, RIKEN has been applied to generate high-biofuels-producing mutants of microalgae species such as Parachlorella kessleri and Euglena gracilis $[63,64]$. At W-MAST, the high cordycepin producing mutants of the medicinal mushroom Cordyceps militaris have been obtained successfully [65]. At HIMAC, the ion beams have been used to clarify the resistance of $B$. subtilis spores to ionizing radiations [66]. More than 20 kinds of useful microorganisms, including bacteria, fungi, and microalgae, have been bred with the ion beams provided by HIRFL [62]. The ion beams have been demonstrated as the effective novel mutagen for breeding technology at these irradiation facilities. These results have attracted much attention in both the industrial and academic fields. We expect that the accessibility of this technology will be ensured in the future by establishing effective utilization systems in the available irradiation facilities, and support systems for users. Ion-beam mutagenic technology in microorganisms would contribute to better human life.

\section{Conclusions}

In this review, the application of ion-beam mutation technology at TIARA for breeding of various microorganisms, such as fungi, algae, and bacteria was described. Mutation breeding is a very important technology to expand the available variety of biological resources. As in the case of higher plants, ion beams cause highly lethal and mutagenic effects, a low multitude of mutations in a locus, and large-scale genomic variations such as large deletions, translocations, and inversions, in microorganisms. Studies described in this review suggest that the application of ion-beam mutagenic technology to microorganisms is useful in both basic science and applied research.

Although it is very important to select the LET of ion beams for effectively inducing a mutation, the differences of mutagenic effects from the different LET of ion beams are poorly understood in a microorganism. In microorganisms, the RBE depended on the LET and the highest RBE values were obtained with ${ }^{12} \mathrm{C}^{5+}$ ion beams $(107 \mathrm{keV} / \mu \mathrm{m}$; Figure 2). LET represents the energy deposition of ionizing radiations on the target. The high density of deposited energy can cause more severe DNA damage. As the large-scale variations can affect the function of many genes, it is expected to obtain the mutants effectively. In tabaco single cells, initial yields of DNA double-strand breaks (DSBs) by the different LET ( 94.8 to $431 \mathrm{keV} / \mu \mathrm{m}$ ) of carbon ion beams depended on LET as well as the RBE based on the lethality, and the highest DSBs yields were obtained at 124 and $241 \mathrm{keV} / \mu \mathrm{m}$ [67]. In $A$. thaliana, it has been shown that carbon ions near the range end $(425 \mathrm{keV} / \mu \mathrm{m})$ frequently cause 
large-scale deletions compared with carbon ions penetrating the seeds $(113 \mathrm{keV} / \mu \mathrm{m})$ [68]. Moreover, in rice, the mutation frequency by the two different LET carbon ion beams (76 and $107 \mathrm{keV} / \mu \mathrm{m})$ has been investigated [69]. The frequency of high LET carbon ion beams was higher than that of the low LET carbon ion beams. These indicate that the LET of ion beams is an important factor for biological effects in a plant. The ${ }^{12} \mathrm{C}^{5+}$ ion beams in anticipation of high mutagenic effects have been usually used for the ion-beam breeding of a microorganism at TIARA. As a result, many mutants have been obtained successfully.

For irradiation to biological samples, at RIBF, five kinds of ion beams $\left({ }^{12} \mathrm{C}^{6+}(23 \mathrm{keV} / \mu \mathrm{m}),{ }^{14} \mathrm{~N}^{7+}\right.$ $(61 \mathrm{keV} / \mu \mathrm{m}),{ }^{20} \mathrm{Ne}^{10+}(62 \mathrm{keV} / \mu \mathrm{m}),{ }^{40} \mathrm{Ar}^{17+}(280 \mathrm{keV} / \mu \mathrm{m})$, and $\left.{ }^{56} \mathrm{Fe}^{24+}(624 \mathrm{keV} / \mu \mathrm{m})\right)$ are used as typical ones. At W-MAST, ${ }^{1} \mathrm{H}^{+}(0.45 \mathrm{keV} / \mu \mathrm{m})$ and ${ }^{12} \mathrm{C}^{6+}(56 \mathrm{keV} / \mu \mathrm{m})$ are used. At HIMAC, five kinds of ion beams $\left({ }^{12} \mathrm{C}^{6+}(13 \mathrm{keV} / \mu \mathrm{m}),{ }^{20} \mathrm{Ne}^{10+}(30 \mathrm{keV} / \mu \mathrm{m}),{ }^{28} \mathrm{Si}^{14+}(54 \mathrm{keV} / \mu \mathrm{m}),{ }^{40} \mathrm{Ar}^{18+}(89 \mathrm{keV} / \mu \mathrm{m})\right.$, and $\left.{ }^{56} \mathrm{Fe}^{26+}(185 \mathrm{keV} / \mu \mathrm{m})\right)$ are used. At HIRFL, ${ }^{12} \mathrm{C}^{6+}$ ion beams (30 to $\left.40 \mathrm{keV} / \mu \mathrm{m}\right)$ are used. The LET ranges of provided ion beams from these facilities differ from those of TIARA. The availability of many different LET ion beams is a great advantage for mutation-breeding technology. The radiosensitivity of microorganisms to ion beams varies extensively depending on the species. For the effective mutagenesis in a microorganism, the investigation of lethal effects for different LET radiations and the selection of suitable LET value at radiation doses that gave $1 \%-10 \%$ of the surviving fraction for the target microorganisms would be important. Moreover, the genome analyses of the obtained mutants will be helpful to clarify the useful characteristics. Recently, the genome comparison analysis of the thermotolerant $B$. japonicum mutant has been revealed the mutations including an inversion of $1.27 \mathrm{Mb}$ and 18 single base substitutions in the 9.11-Mb chromosome [53]. The genome analyses of the other ion-beam-induced mutants are in progress to clear the differences of mutational functions induced by different LET radiations in microorganisms. Further characterizations of mutations induced by different LET radiations will facilitate a more effective use of ion beams in microorganisms breeding.

Author Contributions: Original Draft Preparation, K.S.; Writing-Review and Editing, K.S. and Y.O.

Funding: This research received no external funding.

Acknowledgments: We greatly thank all researchers who undertook microorganism mutagenesis and breeding using ion beams. We really appreciate Hase, Y., Narumi, I., Nozawa, S., Kobayashi, Y., Sakashita, T., Ito, K., Oshima, A., Toyoshima, Y., Masubuchi, T., Watanabe, T., Ikenaga, H., Hayashi, H., Yokoyama, T., Saito, T., Aino, M., Shimizu, N., Ninomiya, K., Nunoshiba, T., Ogino, C., Kato, Y., Furuta, M., Chikamatsu, G., Onaka, H. and Asamizu, S. because the ion beam breeding technology in microorganisms could not be achieved without them. We thank Edanz Group (www.edanzediting.com/ac) for editing a draft of this manuscript.

Conflicts of Interest: The authors declare no conflict of interest.

\section{References}

1. The Joint FAO/IAEA Mutant Variety Database. Available online: https://mvd.iaea.org/ (accessed on 6 March 2019).

2. Kurashima, S.; Satoh, T.; Saitoh, Y.; Yokota, W. Irradiation facilities of the Takasaki advanced radiation research institute. Quantum Beam Sci. 2017, 1, 2. [CrossRef]

3. Tanaka, A.; Sakamoto, A.; Ishigaki, Y.; Nikaido, O.; Sun, G.; Hase, Y.; Shikazono, N.; Tano, S.; Watanabe, H. An ultraviolet-B-resistant mutant with enhanced DNA repair in Arabidopsis. Plant Physiol. 2002, 129, 64-71. [CrossRef] [PubMed]

4. Sakamoto, A.; Lan, V.T.; Hase, Y.; Shikazono, N.; Matsunaga, T.; Tanaka, A. Disruption of the AtREV3 gene causes hypersensitivity to ultraviolet B light and $\gamma$-rays in Arabidopsis: Implication of the presence of a translesion synthesis mechanism in plants. Plant Cell 2003, 15, 2042-2057. [CrossRef] [PubMed]

5. Kitamura, S.; Shikazono, N.; Tanaka, A. TRANSPARENT TESTA 19 is involved in the accumulation of both anthocyanins and proanthocyanidins in Arabidopsis. Plant J. 2004, 37, 104-114. [CrossRef] [PubMed]

6. Rahman, A.; Nakasone, A.; Chhun, T.; Ooura, C.; Biswas, K.K.; Uchimiya, H.; Tsurumi, S.; Baskin, T.I.; Tanaka, A.; Oono, Y. A small acidic protein 1 (SMAP1) mediates responses of the Arabidopsis root to the synthetic auxin 2,4-dichlorophenoxyacetic acid. Plant J. 2006, 47, 788-801. [CrossRef] 
7. Nikjoo, H.; Uehara, S.; Wilson, W.E.; Hoshi, M.; Goodhead, D.T. Track structure in radiation biology: Theory and applications. Int. J. Radiat. Biol. 1998, 73, 355-364. [CrossRef] [PubMed]

8. Yatagai, F. Mutations induced by heavy charged particles. Biol. Sci. Space 2004, 18, 224-234. [CrossRef]

9. Shikazono, N.; Suzuki, C.; Kitamura, S.; Watanabe, H.; Tano, S.; Tanaka, A. Analysis of mutations induced by carbon ions in Arabidopsis thaliana. J. Exp. Bot. 2005, 56, 587-596. [CrossRef]

10. Shikazono, N.; Yokota, Y.; Kitamura, S.; Suzuki, C.; Watanabe, H.; Tano, S.; Tanaka, A. Mutation rate and novel $t$ t mutants of Arabidopsis thaliana induced by carbon ions. Genetics 2003, 163, 1449-1455.

11. Okamura, M.; Yasuno, N.; Ohtsuka, M.; Tanaka, A.; Shikazono, N.; Hase, Y. Wide variety of flower-color and -shape mutants regenerated from leaf cultures irradiated with ion beams. Nucl. Instrum. Methods Phys. Res. B 2003, 206, 574-578. [CrossRef]

12. Nagatomi, S. Development of flower mutation breeding through ion beam irradiation. Res. J. Food Agric. 2003, 26, 33-38. (In Japanese)

13. Okamura, M.; Tanaka, A.; Momose, M.; Umemoto, N.; da Silva, J.A.T.; Toguri, T. Advances of mutagenesis in flowers and their industrialization. In Floriculture, Ornamental and Plant Biotechnology; da Silva, J.A.T., Ed.; Global Science Books: Isleworth, UK, 2006; Volume I, pp. 619-628.

14. Iizuka, M.; Kimura, Y.; Hase, Y.; Tanaka, A. Mutation induction from osteospermum leaf cultures with ion beam Irradiation. JAEA Takasaki Ann. Rep. 2006, 2005, 81.

15. Taneishi, M.; Katai, H.; Yamada, H.; Otsuka, H.; Hase, Y.; Shikazono, N.; Tanaka, A. Effect of ion beam irradiation on the growth of netted melon (Cucumis melo L.). TIARA Ann. Rep. 2002, 2001, 60-61.

16. Nakai, H.; Watanabe, H.; Kitayama, S.; Tanaka, A.; Kobayashi, Y.; Takahashi, T.; Asai, T.; Imada, T. Studies on induced mutations by ion beam in plant. JAERI TIARA Ann. Rep. 1995, 1994, 34-36.

17. Kitamura, H.; Mori, M.; Sato, D.; Nakagawa, J.; Yoshida, T.; Yoshizawa, K.; Kawai, T.; Hase, Y.; Tanaka, A. Carbon ion beam breeding of rice suitable for low nitrogen input. TIARA Ann. Rep. 2006, 2004, 100-101.

18. Ishikawa, S.; Ishimaru, Y.; Igura, M.; Kuramata, M.; Abe, T.; Senoura, T.; Hase, Y.; Arao, T.; Nishizawa, N.K.; Nakanishi, H. Ion-beam irradiation, gene identification, and marker-assisted breeding in the development of low-cadmium rice. Proc. Natl. Acad. Sci. USA 2012, 109, 19166-19171. [CrossRef]

19. Tanaka, A.; Shikazono, N.; Hase, Y. Studies on biological effects of ion beams on lethality, molecular nature of mutation, mutation rate, and spectrum of mutation phenotype for mutation breeding in higher plants. J. Radiat. Res. 2010, 51, 223-233. [CrossRef]

20. Hamada, N.; Funayama, T.; Wada, S.; Sakashita, T.; Kakizaki, T.; Ni, M.; Kobayashi, Y. LET-dependent survival of irradiated normal human fibroblasts and their descendents. Radiat. Res. 2006, 166, 24-30. [CrossRef]

21. Hase, Y.; Yamaguchi, M.; Inoue, M.; Tanaka, A. Reduction of survival and induction of chromosome aberrations in tobacco irradiated by carbon ions with different linear energy transfers. Int. J. Radiat. Biol. 2002, 78, 799-806. [CrossRef]

22. Tanaka, S.; Fukuda, K.; Nishimura, K.; Watanabe, H.; Yamano, N. IRAC M: A Code System to Calculate Induced Radioactivity Produced by Ions and Neutrons; JAERI-Data/Code 97-019; Japan Atomic Energy Research Institute: Tokyo, Japan, 1997.

23. Machida, M.; Yamada, O.; Gomi, K. Genomics of Aspergillus oryzae: Learning from the history of koji mold and exploration of its future. DNA Res. 2008, 15, 173-183. [CrossRef]

24. Toyoshima, Y.; Takahashi, A.; Tanaka, H.; Watanabe, J.; Mogi, Y.; Yamazaki, T.; Hamada, R.; Iwashita, K.; Satoh, K.; Narumi, I. Lethal and mutagenic effects of ion beams and $\gamma$-rays in Aspergillus oryzae. Mutat. Res. 2012, 740, 43-49. [CrossRef]

25. Imamura, M.; Murata, T.; Akagi, K.; Tanaka, Y.; Imamura, M.; Inoue, K.; Mizuma, N.; Kobayashi, Y.; Watanabe, H.; Hachiya, M.; et al. Relationship between LET and RBE values for Escherichia coli determined using carbon ion beams from the TIARA cyclotron and HIMAC synchrotron. J. Gen. Appl. Microbiol. 1997, 43, 175-177. [CrossRef]

26. Hase, Y.; Satoh, K.; Chiba, A.; Hirano, Y.; Tomita, S.; Saito, Y.; Narumi, K. Experimental Study on the Biological Effect of Cluster Ion Beams in Bacillus subtilis Spores. Quantum Beam Sci. 2019, 3, 8. [CrossRef]

27. Satoh, K.; Tejima, K.; Narumi, I. Lethal effects of different LET radiations in Deinococcus radiodurans. JAEA Takasaki Ann. Rep. 2010, 2009, 80.

28. Ito, K.; Takeichi, J.; Hanya, Y.; Satoh, K.; Hase, Y.; Sakashita, T.; Kobayashi, Y.; Narumi, I. Mutation breeding of koji mold induced by ion beams. JAEA Takasaki Ann. Rep. 2006, 2005, 98. 
29. Matuo, Y.; Nishijima, S.; Hase, Y.; Sakamoto, A.; Tanaka, A.; Shimizu, K. Specificity of mutations induced by carbon ions in budding yeast Saccharomyces cerevisiae. Mutat. Res. 2006, 602, 7-13. [CrossRef] [PubMed]

30. Satoh, K.; Ozawa, S.; Hayashi, H.; Oono, Y. Low cesium-accumulating mutants of Rhodococcus erythropolis CS98 generated by ion beam breeding. QST Takasaki Ann. Rep. 2017, 2016, 105.

31. Sakai, K.; Kobayashi, H.; Ohshima, A.; Kato, S.; Satoh, K.; Hase, Y.; Narumi, I.; Sakashita, T.; Kobayashi, Y. Deletion of minor enzyme activities of Rhizomucor miehei by irradiation of heavy-ion beam. JAEA Takasaki Ann. Rep. 2006, 2005, 97.

32. Sakai, K.; Kobayashi, H.; Ohshima, A.; Kato, S.; Satoh, K.; Narumi, I. Deletion of Minor Enzyme Activities of Rhizomucor miehei by Heavy Ion Beam Irradiation. JAEA Takasaki Ann. Rep. 2007, 2006, 95.

33. Satoh, K.; Tejima, K.; Onodera, T.; Narumi, I. Analysis of mutant frequencies for different LET radiations in Deinococcus radiodurans. JAEA Takasaki Ann. Rep. 2012, 2011, 103.

34. Satoh, K.; Oono, Y. Lethal Effects of gamma rays and carbon ion beam radiations in Bacillus subtilis. QST Takasaki Ann. Rep. 2016, 2015, 135.

35. Amsal, A.; Takigami, M.; Ito, H. Increased digestibility of raw starches by mutant strains of Aspergillus awamori. Food Sci. Technol. Res. 1999, 5, 153-155. [CrossRef]

36. Hanya, Y.; Koyama, T.; Ito, K.; Takeichi, J.; Otsuka, T.; Narumi, I.; Satoh, K.; Kobayashi, Y.; Sakashita, T.; Hase, Y. Koji Mold, Method for Breeding the Same, and Method for Producing Soy Sauce. Japanese Unexamined Patent Application Publication No. JP2009095279A, 5 May 2009. (In Japanese).

37. Ngamnit, S.; Takigami, M.; Suchada, P.; Orawan, S.; Saovapong, C.; Ito, H. Decolorization of dark brown pigments in molasses wastewater by mutant strains of Aspergillus usamii and Coriolus versicolor. Biocontrol Sci. 1999, 4, 109-113.

38. Fitriana, Y.; Shinohara, S.; Satoh, K.; Narumi, I.; Saito, T. Benomyl-resistant Beauveria bassiana (Hypocreales: Clavicipitaceae) mutants induced by ion beams. Appl. Entomol. Zool. 2015, 50, 123-129. [CrossRef]

39. Shinohara, S.; Fitriana, Y.; Satoh, K.; Narumi, I.; Saito, T. Enhanced fungicide resistance in Isaria fumosorosea following ionizing radiation-induced mutagenesis. FEMS Microbiol. Lett. 2013, 349, 54-60. [PubMed]

40. Fitriana, Y.; Satoh, K.; Narumi, I.; Saito, T. Ion-beam and gamma-ray irradiation induces thermotolerant mutants in the entomopathogenic fungus Metarhizium anisopliae s.l.. Biocontrol Sci. Technol. 2014, 24, 1052-1061. [CrossRef]

41. Kawashima, Y.; Hase, Y.; Yokota, Y. Development of new commercial strains in functional mushroom by ion beam irradiation. JAEA Takasaki Ann. Rep. 2008, 2007, 76. (In Japanese)

42. Ogino, C.; Yamada, R.; Satoh, K.; Oono, Y. Screening of yeast strain for ethanol fermentation after carbon ion beam irradiation. JAEA Takasaki Ann. Rep. 2015, 2013, 122.

43. Masubuchi, T.; Satoh, K.; Narumi, I.; Kamiyama, O. Ion beam breeding of "Sake Yeast". Bioindustry 2013, 30, 65-71. (In Japanese)

44. Ito, K.; Hanya, Y.; Satoh, S.; Hase, Y.; Narumi, I. Mutation breeding of Zygosaccharomyces rouxii induced by ion beams. JAEA Takasaki Ann. Rep. 2009, 2008, 83.

45. Kato, Y.; Ho, S.H.; Vavricka, C.J.; Chang, J.S.; Hasunuma, T.; Kondo, A. Evolutionary engineering of salt-resistant Chlamydomonas sp. strains reveals salinity stress-activated starch-to-lipid biosynthesis switching. Bioresour. Technol. 2017, 245, 1484-1490. [CrossRef] [PubMed]

46. Araie, H.; Hase, Y.; Oono, Y.; Suzuki, I.; Shiraiwa, Y. Breeding of the oil-producing algae by heavy ion beam irradiation. QST Takasaki Ann. Rep. 2018, 2016, 95.

47. Takeda, K.; Satoh, K.; Narumi, I.; Ohtsu, N.; Yokoyama, T. Identification of DNA mutation sites in a high temperature tolerant mutant of Bradyrhizobium japonicum USDA110 generated by ion-beam irradiation. JAEA Takasaki Ann. Rep. 2014, 2012, 114.

48. Satoh, K.; Ueda, R.; Hase, Y.; Narumi, I.; Oono, Y. Development of cesium-accumulating bacteria by ion beam breeding technology. JAEA Takasaki Ann. Rep. 2015, 2013, 117.

49. Aino, M.; Matsuura, K.; Satoh, K.; Narumi, I. Characteristics of mutant endophytic bacteria strains improved using ion beams. JAEA Takasaki Ann. Rep. 2011, 2010, 109. (In Japanese)

50. Yanagisawa, M.; Asamizu, S.; Sugai, Y.; Satoh, K.; Oono, Y.; Onaka, H. Screening of mutants generated by heavy ion beam for identification of genes involved in bacterial interaction. QST Takasaki Ann. Rep. 2017, $2016,97$. 
51. Masubuchi, T.; Takashima, C.; Kamiyama, O.; Ikenaga, H.; Satoh, K.; Narumi, I. Identification of mutation sites in high ethyl caproate producing sake yeasts generated by ion beam breeding. JAEA Takasaki Ann. Rep. 2012, 2011, 110. (In Japanese)

52. Akada, R.; Matsuo, K.; Aritomi, K.; Nishizawa, Y. Construction of recombinant sake yeast containing a dominant FAS2 mutation without extraneous sequences by a two-step gene replacement protocol. J. Biosci. Bioeng. 1999, 87, 43-48. [CrossRef]

53. Takeda, K.; Satoh, K.; Narumi, I.; Oono, Y.; Ohkama-Ohtsu, N.; Yokoyama, T. Genome analysis of the high temperature tolerant mutant of Bradyrhizobium japonicum USDA110 generated by ion-beam irradiation. JAEA Takasaki Ann. Rep. 2015, 2013, 120.

54. Tomioka, N.; Uchiyama, H.; Yagi, O. Isolation and characterization of cesium-accumulating bacteria. Appl. Environ. Microbiol. 1992, 58, 1019-1023.

55. Satoh, K.; Ueda, R.; Hase, Y.; Narumi, I.; Oono, Y. Screening of cesium-accumulating mutant of radioresistant bacterium Deinococcus radiodurans by ion beam breeding technology. JAEA Takasaki Ann. Rep. 2016, 2014, 100.

56. Azhar, S.H.M.; Abdulla, R.; Jambo, S.A.; Marbawi, H.; Gansau, J.A.; Faik, A.A.M.; Rodrigues, K.F.; Ogino, C.; Yamada, R.; Satoh, K.; et al. Yeasts in sustainable bioethanol production: A review. Biochem. Biophys. Rep. 2017, 10, 52-61.

57. Ogino, C.C.; Kahar, P.; Lee, J.M.; Satoh, K.; Oono, Y.; Kondo, A. Breeding of high ethanol producing yeast by screening from mutant library. JAEA Takasaki Ann. Rep. 2016, 2014, 105.

58. Benedetti, M.; Vecchi, V.; Barera, S.; Dall'Osto, L. Biomass from microalgae: The potential of domestication towards sustainable biofactories. Microb. Cell Fact. 2018, 17, 173. [CrossRef] [PubMed]

59. RIKEN Nishina Center for Accelerator-Based Science. Available online: https://www.nishina.riken.jp/index_ e.html (accessed on 6 March 2019).

60. The Wakasa Wan Energy Research Center. Available online: http://www.werc.or.jp/enenews/pdf/pamphlet_ english.pdf (accessed on 6 March 2019).

61. National Institute of Radiological Sciences. Available online: https://www.nirs.qst.go.jp/ENG/index.html (accessed on 6 March 2019).

62. Hu, W.; Li, W.; Che, J. Recent advances of microbial breeding via heavy-ion mutagenesis at IMP. Lett. Appl. Microbiol. 2017, 65, 274-280. [CrossRef]

63. Ota, S.; Matsuda, T.; Takeshita, T.; Yamazaki, T.; Kazama, Y.; Abe, T.; Kawano, S. Phenotypic spectrum of Parachlorella kessleri (Chlorophyta) mutants produced by heavy-ion irradiation. Bioresour Technol. 2013, 49, 432-438. [CrossRef] [PubMed]

64. Yamada, K.; Suzuki, H.; Takeuchi, T.; Kazama, Y.; Mitra, S.; Abe, T.; Goda, K.; Suzuki, K.; Iwata, O. Efficient selective breeding of live oil-rich Euglena gracilis with fluorescence-activated cell sorting. Sci. Rep. 2016, 6, 26327. [CrossRef] [PubMed]

65. Das, S.K.; Masuda, M.; Sakurai, A.; Sakakibara, M. Effects of additives on cordycepin production using a Cordyceps militaris mutant induced by ion beam irradiation. Afr. J. Biotechnol. 2009, 8, 3041-3047.

66. Moeller, R.; Raguse, M.; Reitz, G.; Okayasu, R.; Li, Z.; Klein, S.; Setlow, P.; Nicholsone, W.L. Resistance of Bacillus subtilis spore DNA to lethal ionizing radiation damage relies primarily on spore core components and DNA repair, with minor effects of oxygen radical detoxification. Appl. Environ. Microbiol. 2014, 80, 104-109. [CrossRef]

67. Yokota, Y.; Yamada, S.; Hase, Y.; Shikazono, N.; Narumi, I.; Tanaka, A.; Inoue, M. Initial yields of DNA double-strand breaks and DNA fragmentation patterns depend on linear energy transfer in tobacco BY-2 protoplasts irradiated with helium, carbon and neon ions. Radiat. Res. 2007, 167, 94-101. [CrossRef] [PubMed]

68. Hase, Y.; Yoshihara, R.; Nozawa, S.; Narumi, I. Mutagenic effects of carbon ions near the range end in plants. Radiat. Res. 2012, 731, 41-47. [CrossRef] [PubMed]

69. Yamaguchi, H.; Hase, Y.; Tanaka, A.; Shikazono, N.; Degi, K.; Shimizu, A.; Morishita, T. Mutagenic effects of ion beam irradiation on rice. Breed. Sci. 2009, 59, 169-177. [CrossRef]

(C) 2019 by the authors. Licensee MDPI, Basel, Switzerland. This article is an open access article distributed under the terms and conditions of the Creative Commons Attribution (CC BY) license (http://creativecommons.org/licenses/by/4.0/). 